\title{
Nitric Oxide and Peroxynitrite Regulate Transporter Transcription in Rat Liver Slices
}

\author{
Kimiko Aoki, ${ }^{* a, b}$ Naomi Saso, ${ }^{a}$ Satoko Kato,,${ }^{a}$ Yuichi SugiYama,,${ }^{c}$ and Hitoshi Sato ${ }^{a}$ \\ ${ }^{a}$ School of Pharmaceutical Sciences, Showa University; 1-5-8 Hatanodai, Shinagawa-ku, Tokyo 142-8555, Japan: \\ ${ }^{b}$ Nihon Pharmaceutical University; 10281 Komuro, Inamachi, Kitaadachi-gun, Saitama 362-0806, Japan: and ${ }^{c}$ Graduate \\ School of Pharmaceutical Sciences, University of Tokyo; 7-3-1 Hongo, Bunkyo-ku, Tokyo 113-0033, Japan. \\ Received April 7, 2008; accepted July 24, 2008; published online July 28, 2008
}

To determine the role of nitric oxide (NO) in rat liver transporter regulation, we investigated in precisioncut liver slices the effect of $\mathrm{NO}$ and peroxynitrite $\left(\mathrm{ONOO}^{-}\right)$, a reaction product of $\mathrm{NO}$ with superoxide $\left(\mathrm{O}_{2}^{-}\right)$, on mRNA levels of 13 influx and efflux transporters. To inactivate Kupffer cells (KCs), liver slices were prepared from rats treated with gadolinium chloride (Gd). Transporter mRNA levels were determined after incubation of untreated (normal-slices) and Gd-pretreated slices (Gd-slices) for $18 \mathrm{~h}$ with Spermine NONOate (SpNO), an NO donor, and SIN-1 (3-(4-morpholinyl) sydnonimine hydrochloride, SIN), a ONOO' ${ }^{-}$donor. SpNO and SIN varied all transporter mRNA levels examined, except organic anion transporting polypeptide 1 b2 (Oatp1b2/Oatp4). SpNO in normal-slices and SIN in Gd- and normal-slices generally decreased influx and increased efflux transporter transcription. In contrast, these effects were not observed in Gd-slices treated with SpNO. SpNO and SIN in normal-slices commonly decreased organic anion transporter 2 (Oat2) and increased multidrug resistance-associated protein 2 (Mrp2) transcription, but differentially regulated bile salt export pump (Bsep) and multidrug resistance protein 2 (Mdr2) transcription, the up-regulation by SpNO and the down-regulation by SIN. In addition, the induction of tumor necrosis factor (TNF)- $\alpha$ and interleukin (IL)- $1 \beta$ was not observed after incubation with SpNO or SIN. These findings suggest that $\mathrm{NO}$ and $\mathrm{ONOO}^{-}$play a role in the regulation of rat transporter transcription in hepatocytes, which communicate with $\mathrm{KCs}$, in a proinflammatory cytokine-independent manner.

Key words nitric oxide; peroxynitrite; rat liver transporter; liver slice; Kupffer cell; lipopolysaccharide

Lipopolysaccharide (LPS) administration to rats results in cholestasis associated with changes in the expression of several liver transporters. ${ }^{1)}$ The down-regulation of canalicular efflux transporters bile salt export pump (Bsep), multidrug resistance-associated protein 2 (Mrp2) and multidrug resistance protein 1a (Mdr1a), which causes cholestasis, is thought to be compensated by down-regulation of basolateral influx transporters, as well as up-regulation of basolateral and canalicular efflux transporter, Mrp3 and Mdr1b, which protect the liver from the accumulation of endogenous compounds, such as bile acid and bilirubin, as well as exogenous toxic compounds.

LPS activates the production of proinflammatory cytokines and nitric oxide (NO) in the liver (Fig. 1A). The first LPS action is the induction of proinflammatory cytokine production, including tumor necrosis factor (TNF)- $\alpha$ and interleukin (IL)- $1 \beta$, in Kupffer cells (KCs), resident macrophages in the sinusoid of the liver, via toll-like receptor signaling. Subsequently, proinflammatory cytokines released from KCs lead to the induction of inducible NO synthase (iNOS) to produce $\mathrm{NO}$ in hepatocytes and $\mathrm{KCs} .^{2)}$ Furthermore, NO reacts with superoxide anion $\left(\mathrm{O}_{2}^{-}\right)$, derived from $\mathrm{KCs}$ and produced from mitochondria stimulated by $\mathrm{NO}$, to form peroxynitrite $\left(\mathrm{ONOO}^{-}\right)^{3)}$

Proinflammatory cytokines are known as major mediators in transcriptional regulation of liver transporter genes, including $\mathrm{Na}^{+}$-taurocholate cotransporting polypeptide (Ntcp), organic anion transporting polypeptides (Oatp1a1/Oatp1, Oatp1a4/Oatp2), Mrp2, Mrp3, Bsep, Mdr1a and Mdr1b.,5) Although NO inhibits nuclear factor (NF)- $\kappa$ B activation ${ }^{6}$ and transcriptional activities of nuclear receptors such as retinoid X receptor (RXR) and hepatocyte nuclear factor
(HNF) $4 \alpha,{ }^{7,8)}$ which regulate rat liver transporter transcription. $\left.{ }^{9}\right)$ However, the role of NO has been demonstrated only in the regulation of organic anion transporter 2 (Oat2) transcription in liver. ${ }^{10)}$ In a previous report, we showed the possible regulation of rat liver transporter transcription by both proinflammatory cytokines and NO in vivo, the specific roles of which could not be separately determined. ${ }^{11)}$

Recently, precision-cut liver slices have shown potential in the study of biological phenomena under the control of hepatocytes and nonparenchymal cells due to the preservation of the original cellular architecture and cell interactions within the slice. ${ }^{12)}$ Here, we used precision-cut slices to investigate the role of $\mathrm{NO}$ and $\mathrm{ONOO}^{-}$in transcriptional regulation of basolateral influx transporters (Ntcp, Oatp1a1, Oatp1a4, Oatp1b2/Oatp4, Oat2, Oat3, organic cation transporter 1 (Oct1)), canalicular efflux transporters (Mrp2, Bsep, Mdr1a, Mdr1b, Mdr2), and basolateral efflux transporter Mrp3 (Fig. 1B). To clarify the role of $\mathrm{KCs}$ in $\mathrm{NO}$ and $\mathrm{ONOO}^{-}$action, we also used gadolinium chloride-pretreated slices (Gdslices), in which gadolinium chloride hexahydrate (Gd) leads to a decrease of proinflammatory cytokine, $\mathrm{O}_{2}^{-}$and NO production by KCs. ${ }^{13-15)}$

\section{MATERIALS AND METHODS}

Reagents Lipopolysaccharide (LPS, Escherichia coli, serotype 0111:B4) and William's medium E (WME) were purchased from Sigma-Aldrich (MO, U.S.A.); spermine NONOate ( $N$-[4-[1-(3-aminopropyl)-2-hydroxy-2-nitrosohydrazino] butyl]-1,3-propanediamin, SpNO) from Cayman Chemicals (MI, U.S.A.); SIN-1 (3-(4-morpholinyl) sydnonimine hydrochloride, SIN), Gd, kanamycin monosulfate and 

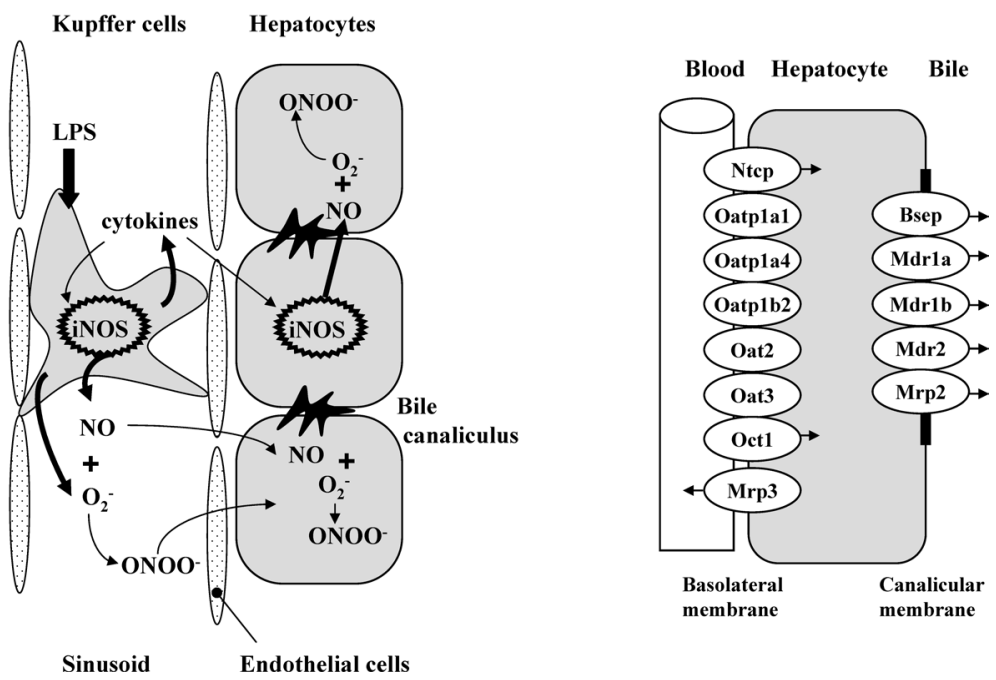

Fig. 1. Schematic Diagrams of $\mathrm{NO}$ and $\mathrm{ONOO}^{-}$Production by Kupffer Cells (KCs) and Hepatocytes (A) and Rat Liver Transporters Expressed on Basolateral and Canalicular Membrane of Hepatocyte (B)

(A) Cytokines released from activated $\mathrm{KCs}$ induce iNOS expression in $\mathrm{KCs}$ and hepatocytes. ${ }^{2)} \mathrm{O}_{2}^{-}$is produced by NADPH oxidase in $\mathrm{KCs}$. NO stimulates $\mathrm{O}_{2}^{-}$production from mitochondria, via inhibition of the respiratory chain and reaction with ubiquinol. NO reacts with $\mathrm{O}_{2}^{-}$to produce $\mathrm{ONOO}^{-}$in sinusoid and in hepatocytes. ${ }^{3)}$ (B) Ntcp, Oatpla1, Oatp1a4, Oatp1b2, Oat2, Oat3 and Oct1 on basolateral membrane are involved in substrate influx from portal blood into hepatocytes, although Oatps and Oats are also involved in substrate influx ${ }^{34)}$ Bsep, Mdrla, Mdr1b and Mrp2 on canalicular membrane are involved in the efflux of substrate into bile, while Mrp3 mediates basolateral efflux into blood. Mdr2 is phospholipids transporter. ${ }^{9}$ Arrows indicate the direction of transport. Bidirectional transporters are shown without arrows.

Transaminase CII-test Wako from Wako Pure Chemical Industries (Osaka, Japan); Via Span ${ }^{\circledR}$ (BELZER UW) from Fujisawa Pharmaceutical Co. (Osaka, Japan); and ISOGEN and $\mathrm{qPCR}^{\mathrm{TM}}$ Mastermix Plus for SYBR ${ }^{\circledR}$ Green I from Nippon Gene (Tokyo, Japan). All other reagents were of analytical grade.

Preparation and Incubation of Rat Liver Slices Precision-cut liver slices were prepared and incubated according to the method described by Elferink et al. ${ }^{16)}$ Gd-slices and normal-slices from two groups of male Sprague-Dawley rats weighing between 200 and $300 \mathrm{~g}$ (Sankyo Laboratories, Tokyo, Japan) were obtained by intravenous (i.v.) injection of saline and $\mathrm{Gd}(10 \mathrm{mg} / \mathrm{kg}),{ }^{17)}$ respectively, in the tail vein $24 \mathrm{~h}$ before liver isolation. Liver slices of $300-\mu \mathrm{m}$ thickness were prepared from liver cores of $8 \mathrm{~mm}$ in diameter using a precision-cut slicer (linear slicer Pro7; Dosaka EM, Kyoto, Japan) and stored in ice-cold organ preservation solution (Via $\operatorname{Span}^{\circledR}$ ) until use. Each slice was added to $3.2 \mathrm{ml}$ of WME supplemented with $25 \mathrm{~mm}$ D-glucose, $50 \mu \mathrm{g} / \mathrm{ml}$ kanamycin and $200 \mathrm{~mm}$ glutamine (culture medium) in individual wells of six-well plates. Plates were placed in a plastic container and incubated with shaking under a continuous $95 \% \mathrm{O}_{2} / 5 \%$ $\mathrm{CO}_{2}$ flow at $37^{\circ} \mathrm{C}$. Slices were incubated in $3.3 \mathrm{ml}$ of medium with or without LPS $(100 \mu \mathrm{g} / \mathrm{ml}), \operatorname{SpNO}(0.5 \mathrm{~mm})$ or SIN $(2 \mathrm{~mm})$ for $18 \mathrm{~h}$. After incubation, liver slices were quickly frozen in liquid nitrogen and stored at $-80^{\circ} \mathrm{C}$, while the culture medium was stored at $-30^{\circ} \mathrm{C}$. Slices from the same liver were used in the corresponding control and treated groups. Experimental protocols were approved by the Showa University Animal Research Committee.

$\mathrm{NO}_{2}^{-} / \mathrm{NO}_{3}^{-}$Level and Aspartate Aminotransferase Activity in Culture Medium After reduction of $\mathrm{NO}_{3}^{-}$to $\mathrm{NO}_{2}^{-}$ by nitrate reductase in the $40-\mu \mathrm{l}$ culture medium, $\mathrm{NO}_{2}^{-}$levels were measured by Griess assay. ${ }^{18)}$ Aspartate aminotransferase (AST) activity of the culture medium (10 $\mu \mathrm{l})$ was measured by Transaminase CII-test Wako.

RNA Isolation and Reverse Transcriptase-Polymerase Chain Reaction (RT-PCR) Analysis Total RNA from two combined liver slices was isolated using ISOGEN and RTPCR analysis was carried out as previously described. ${ }^{11}$ Real-time PCR was conducted using qPCR Mastermix Plus for SYBR green I. Primers were designed using Primer Express software (Applied Biosystems, Japan) and human $\beta$ actin cDNA, used as a standard template for the ABI Prism 7000 sequence detection system (Applied Biosystems, Japan). mRNA levels were expressed as a ratio to that of glyceraldehyde-3-phosphate dehydrogenase (GAPDH).

Statistical Analysis Statistical analysis was conducted using one-way analysis of variance (ANOVA), followed by Fisher's LSD post hoc test, with differences considered significant at $p<0.05$. Results are expressed as mean \pm S.E.M.

\section{RESULTS}

Variation in Transporter mRNA Levels in NormalSlices during 18-h Incubation in the Absence of Stimulants mRNA levels of rat liver transporters have been reported to vary in primary cultured hepatocytes. ${ }^{19-22)}$ Based on these findings, we measured mRNA levels of transporters in normal-slices $0 \mathrm{~h}$ and $18 \mathrm{~h}$ after incubation (Fig. 2A). Results show that compared to levels at $0 \mathrm{~h}, \mathrm{mRNA}$ levels of Ntcp, Oatp1a4, Oatp1b2, Oat2, Oct1, Bsep and Mrp2 decreased, while those of Mdr1a and Mdr1b increased after an $18-\mathrm{h}$ incubation period. In particular, Mdrlb mRNA levels increased to 1280 -fold. Consistent with our results, the down-regulation of influx transporter ${ }^{19-21)}$ and the strong induction of Mdr1b expression ${ }^{22}$ have been found in primary cultured hepatocytes. In addition, a $65-79 \%$ increase in TNF- $\alpha$, IL- $1 \beta$ and iNOS mRNA levels was observed during the incubation period, with change in iNOS not considered 

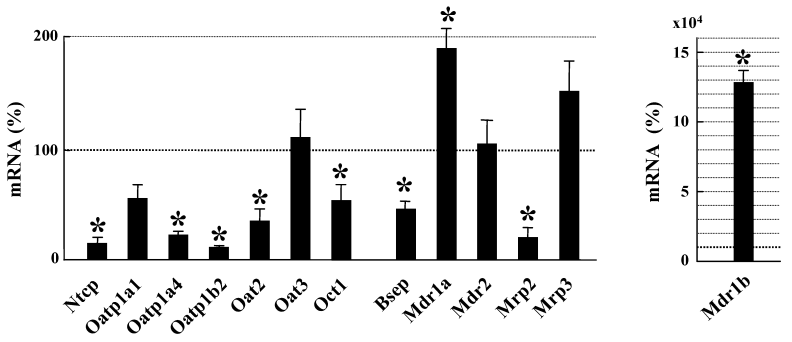

B

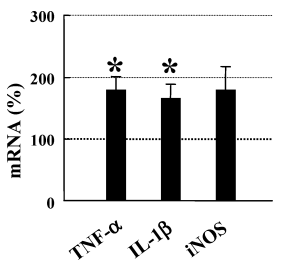

Fig. 2. Variation in mRNA Levels of Transporter, TNF- $\alpha$, IL-1 $\beta$ and iNOS in Normal-Slices during 18-h Incubation in the Absence of Stimulants

mRNA levels in normal-slices were measured at $0 \mathrm{~h}$ and $18 \mathrm{~h}$ after incubation. (A) Transporters. (B) TNF- $\alpha$, IL- $1 \beta$ and iNOS. mRNA data at $18 \mathrm{~h}$, normalized to that of GAPDH, are expressed as a percentage of results at $0 \mathrm{~h}$. Each bar represents mean \pm S.E.M. $(n=3-5) . * p<0.05$ compared with $0 \mathrm{~h}$.

Table 1. Effects of LPS on mRNA Levels of TNF- $\alpha$, IL- $1 \beta$ and iNOS in Normal-Slices, as well as $\mathrm{NO}_{2}^{-} / \mathrm{NO}_{3}^{-}$Levels and AST Activities in Culture Medium

\begin{tabular}{lcc}
\hline \hline & Control $(n)$ & LPS $(n)$ \\
\hline mRNA levels in slices & & \\
TNF- $\alpha(\%)$ & $100 \pm 28(3)$ & $427 \pm 163(5)$ \\
IL-1 $\beta(\%)$ & $100 \pm 20(3)$ & $342 \pm 12(3)^{*}$ \\
iNOS (\%) & $100 \pm 16(3)$ & $1730 \pm 336(3)^{*}$ \\
Culture medium & & \\
$\mathrm{NO}_{2}^{-} / \mathrm{NO}_{3}^{-}(\mu \mathrm{M})$ & $13.5 \pm 1.2(5)$ & $75.6 \pm 6.3(5)^{*}$ \\
$\mathrm{AST}^{*}$ activity $(\mathrm{IU} / \mathrm{l})$ & $18.0 \pm 2.6(5)$ & $39.0 \pm 5.7(5)^{*}$
\end{tabular}

Normal-slices were incubated with or without LPS $(100 \mu \mathrm{g} / \mathrm{ml})$ for $18 \mathrm{~h}$. mRNA data, normalized to that of GAPDH, are expressed as a percentage of controls. $* p<0.05$ compared with controls.

significant (Fig. 2B).

Inflammatory Responses and Transporter Transcription of Normal-Slices Treated with LPS KCs release proinflammatory cytokines, including TNF- $\alpha$ and IL- $1 \beta$, in response to LPS. Successively, proinflammatory cytokines from $\mathrm{KCs}$ mediate the induction of iNOS expression and NO production in $\mathrm{KCs}$ and hepatocytes in an autocrine and a paracrine manner. ${ }^{2)}$ IL- $1 \beta$ is almost exclusively and TNF- $\alpha$ is mainly produced by $\mathrm{KCs}^{23}$ ) Therefore, we measured mRNA levels of TNF- $\alpha$, IL- $1 \beta$ and iNOS in slices and NO $\left(\mathrm{NO}_{2}^{-} / \mathrm{NO}_{3}^{-}\right)$levels in culture medium after an 18 -h incubation period with or without LPS $(100 \mu \mathrm{g} / \mathrm{ml})$ to confirm the function of KCs in normal-slices (Table 1). LPS increased mRNA levels of IL- $1 \beta$ and TNF- $\alpha$, but the latter change is not significant, accompanied with NO production to $75.6 \mu \mathrm{M}$ via induction of iNOS transcription. Concomitantly, LPS decreased mRNA levels of all basolateral influx transporters and canalicular efflux transporter Mdr2 and Mrp2 in hepatocytes (Fig. 3). These results indicate that KCs function is retained and $\mathrm{KCs}$ interact with hepatocytes in normal-slices, as described by Olinga et al. ${ }^{12)}$

Effect of SpNO and SIN on TNF- $\alpha$, IL-1 $\beta$ and iNOS

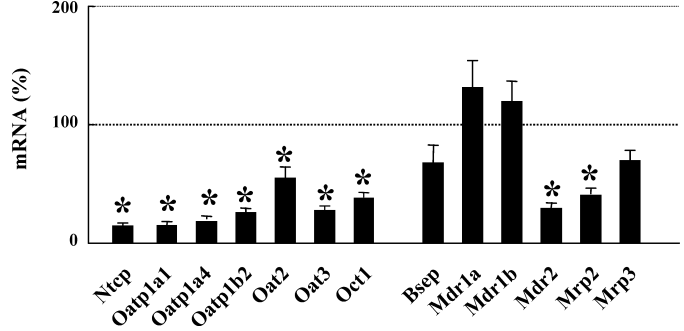

Fig. 3. Effects of LPS on Transporter mRNA Levels in Normal-Slices

Normal-slices were incubated with or without LPS $(100 \mu \mathrm{g} / \mathrm{ml})$ for $18 \mathrm{~h}$. mRNA data, normalized to that of GAPDH, are expressed as a percentage of controls. Each bar represents mean \pm S.E.M. $(n=3-5)$. $* p<0.05$ compared with controls.

A
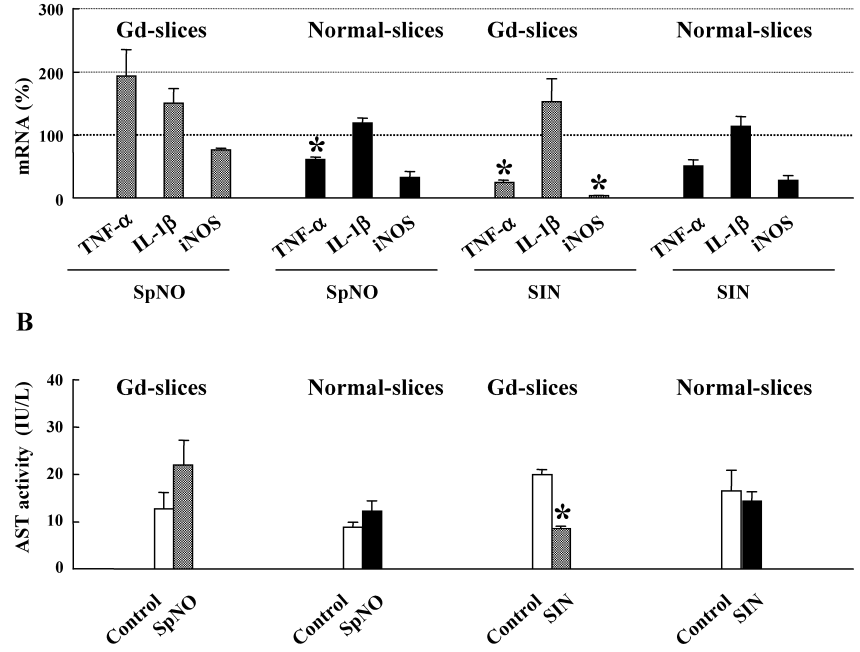

Fig. 4. Effects of SpNO and SIN on mRNA Levels of TNF- $\alpha$, IL- $1 \beta$ and iNOS in Gd- and Normal-Slices, as well as AST Activities in Culture Medium

Gd- and normal-slices were incubated with or without SpNO $(0.5 \mathrm{~mm})$ or SIN $(2 \mathrm{~mm})$ for $18 \mathrm{~h}$. (A) TNF- $\alpha$, IL- $1 \beta$ and iNOS mRNA levels in slices. mRNA data in treated groups, normalized to that of GAPDH, are expressed as a percentage of controls. (B) AST activities in culture medium. Each bar represents mean \pm S.E.M. $(n=3-5)$ $* p<0.05$ compared with controls.

mRNA Levels in Gd- and Normal-Slices Proinflammatory cytokines such as TNF- $\alpha$ and IL- $1 \beta$ are known to regulate transporter mRNA expression. ${ }^{4,5)}$ In addition, NO donors have been reported to stimulate TNF- $\alpha$ production in macrophages. ${ }^{24)}$ Based on these findings, we measured mRNA levels of TNF- $\alpha$, IL- $1 \beta$ and iNOS in Gd- and normal-slices after an 18-h incubation period with or without SpNO (0.5 mM) or SIN (2 mm) (Fig. 4A).

SpNO and SIN decreased TNF- $\alpha$ mRNA levels in normaland Gd-slices, respectively. iNOS mRNA levels were also decreased to $2.8 \%$ in Gd-slices with SIN, whereas IL- $1 \beta$ mRNA levels were not affected by SpNO and SIN. Further, no increase in AST activities was observed with SpNO or SIN (Fig. 4B). Although previous studies mention that $\mathrm{ONOO}^{-}$is a key mediator of cytotoxicity, ${ }^{25)}$ the present results show that SIN decreased AST activities in Gd-slices. These results indicate that SpNO $(0.5 \mathrm{~mm})$ and SIN (2 mM) have no liver toxicity and that their effects are independent of proinflammatory cytokines.

Effect of SpNO on Transporter mRNA Levels in Gdand Normal-Slices To investigate the effect of $\mathrm{NO}$ and $\mathrm{KCs}$ on transporter transcription, Gd- and normal-slices were 
incubated with or without SpNO (Fig. 5). SpNO increased mRNA levels of basolateral influx transporter Oatpla1 and decreased those of canalicular efflux transporter of Mdr2 in Gd-slices (Fig. 5A). In contrast, mRNA levels of basolateral influx transporter (Ntcp, Oatp1a4, Oat2, Oct1) decreased and those of canalicular efflux transporter (Bsep, Mdr2, Mrp2) increased in normal-slices with SpNO (Fig. 5B). In both slices treated with SpNO, mRNA levels of Oatp1b2, Oat3, Mdr1a, Mdr1b and Mrp3 were not affected.

Effect of SIN on Transporter mRNA Levels in Gd- and Normal-Slices To investigate the roles of $\mathrm{ONOO}^{-}$and $\mathrm{KCs}$ in the regulation of transporter transcription, Gd- and normal-slices were incubated with or without SIN (Fig. 6). SIN in Gd- and normal-slices generally decreased mRNA levels of basolateral influx transporters and increased those of efflux transporters as well as SpNO in normal-slices. In

A. SpNO/Gd-slices
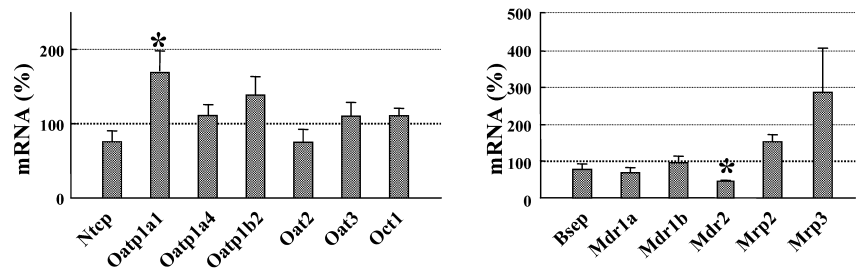

B. SpNO/Normal-slices
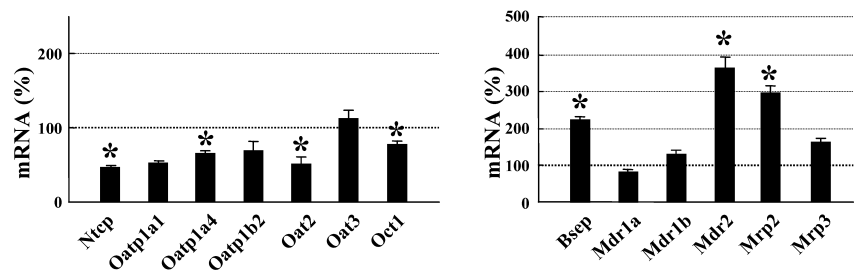

Fig. 5. Effects of SpNO on Transporter mRNA Levels in Gd- and Nor mal-Slices

Gd- and normal-slices were incubated with or without SpNO $(0.5 \mathrm{~mm})$ for $18 \mathrm{~h}$. (A) Transporter mRNA levels in Gd-slices. (B) Transporter mRNA levels in normal-slices. mRNA data in treated groups, normalized to that of GAPDH, are expressed as a percentage of controls. Each bar represents mean \pm S.E.M. $(n=3-5)$. $* p<0.05$ compared with controls.
Gd-slices treated with SIN, mRNA levels of basolateral influx transporter (Oatp1a1, Oat2, Oat3, Oct1) decreased, while those of canalicular efflux transporter (Mdr1a, Mrp2) and basolateral influx transporter Mrp3 increased, but with exceptional up-regulation of Ntcp transcription (Fig. 6A). In normal-slices treated with SIN, mRNA levels of basolateral influx transporter (Oatp1a1, Oatp1a4, Oat2) decreased, while those of canalicular efflux transporter (Mdr1a, Mdr1b, Mrp2) and basolateral efflux transporter Mrp3 increased, but with exceptional down-regulation of canalicular efflux transporter (Bsep, Mdr2) transcription (Fig. 6B). In both slices treated with SIN, no effect on Oatp1b2 mRNA levels was observed.

\section{DISCUSSION}

In the present study, the effects of SpNO (NO donor) and SIN (ONOO ${ }^{-}$donor) on mRNA levels of 13 transporters in rat liver slices are detailed (Table 2). The results show that transporter transcription pattern varies among Gd- and normal-slices treated with SpNO and SIN. The down-regulation of influx and the up-regulation of efflux transporters appear to represent a general pattern in normal-slices with SpNO or SIN and Gd-slices with SIN. SpNO and SIN in normal-slices commonly decreased Oat 2 and increased Mrp2 transcription, but differentially regulated Bsep and Mdr2 transcription, the up-regulation by $\mathrm{SpNO}$ and the down-regulation by SIN. These data suggest that $\mathrm{NO}$ and $\mathrm{ONOO}^{-}$may play an important role in the regulation of transporter transcription in hepatocytes communicated with KCs.

The 18-h incubation of normal-slices strongly increased basal (intrinsic) mRNA levels of Mdr1b, moderately increased those of Mdr1a and had no effects on those of Mdr2 (Fig. 2). These different changes of Mdr isoforms are consistent with the results in primary cultured rat hepatocytes. ${ }^{26}$ The super-induction of basal Mdr1b mRNA levels was also observed in primary cultured rat hepatocytes, ${ }^{22)}$ but to a lesser extent (50-100-fold induction) than that in normalslices (1280-fold), suggesting the enhancement by KCs. Mdr1b transcription is up-regulated by NF- $\kappa \mathrm{B}$ activated by reactive oxygen species (ROS) or TNF- $\alpha .^{26,27)}$ Similar to
A. SIN/Gd-slices

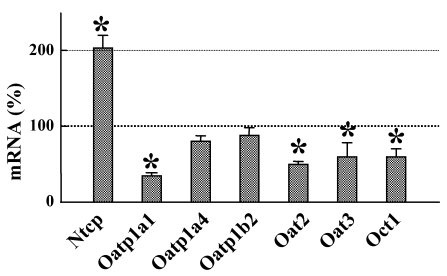

B. SIN/Normal-slices

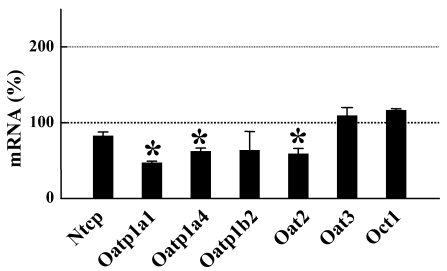

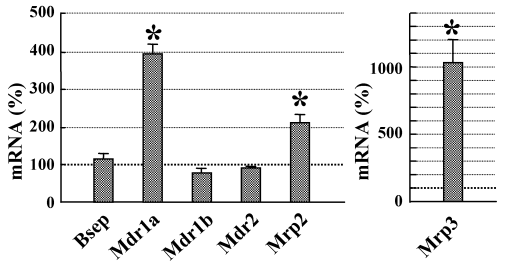

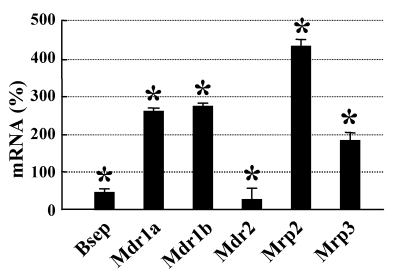

Fig. 6. Effects of SIN on Transporter mRNA Levels in Gd- and Normal-Slices

Gd- and normal-slices were incubated with or without SIN (2 mM) for $18 \mathrm{~h}$. (A) Transporter mRNA levels in Gd-slices. (B) Transporter mRNA levels in normal-slices. mRNA data in treated groups, normalized to that of GAPDH, are expressed as a percentage of controls. Each bar represents mean \pm S.E.M. $(n=3-5)$. $* p<0.05$ compared with controls. 
Table 2. Summary for Transporter Transcription Changes in Gd- and Normal-Slices Treated with SpNO or SIN

\begin{tabular}{|c|c|c|c|c|}
\hline \multirow{2}{*}{ Transporter } & \multicolumn{2}{|c|}{ SpNO } & \multicolumn{2}{|r|}{ SIN } \\
\hline & Gd-slices & Normal-slices & Gd-slices & Normal-slices \\
\hline Ntcp & & $\nabla$ & $\triangle$ & \\
\hline Oatp1a1 & $\Delta$ & & $v$ & \\
\hline Oatp1a4 & & $\nabla$ & & $\nabla$ \\
\hline Oatp1b2 & & & & \\
\hline Oat2 & & $\nabla$ & $\nabla$ & $\nabla$ \\
\hline Oat3 & & & $v$ & \\
\hline Oct1 & & $\nabla$ & $\nabla$ & \\
\hline Bsep & & $\widehat{\Delta}$ & & $\nabla$ \\
\hline Mdr1a & & & $\Delta$ & $\Delta$ \\
\hline Mdr1b & & & & $\Delta$ \\
\hline Mdr2 & $=$ & $\widehat{\Delta}$ & & $\nabla$ \\
\hline Mrp2 & & $\Delta$ & $\Delta$ & $\widehat{\Delta}$ \\
\hline Mrp3 & & & $\Delta$ & $\Delta$ \\
\hline
\end{tabular}

Mdr1b, TNF- $\alpha$ and iNOS are NF- $\kappa$ B-dependent genes. ${ }^{28,29)}$ Only 79\% increase in TNF- $\alpha$ and iNOS mRNA levels after incubation of normal-slices for $18 \mathrm{~h}$ suggests mechanism other than NF- $\kappa \mathrm{B}$ activation to explain the strong induction of Mdrlb transcription. As previously suggested for the super-induction in cultured hepatocytes, the super-induction of Mdrlb may be a consequence of reduced antioxidant capacity during incubation. ${ }^{26)}$

Transporter mRNA levels varied with the induction of cytokines and iNOS in normal-slices in response to LPS (Table 1, Fig. 3). LPS-induced cholestasis in rats constantly results in the down-regulation of Ntcp, Oatps and Mrp2, and the upregulation of Mdr1b. ${ }^{1,411)}$ Inconsistently with these in vivo results, Mdrlb mRNA levels were shown not to change in normal-slices treated with LPS, suggesting a possibility that LPS effects on Mdrlb may be masked by the super-induction of Mdr1b transcription during the incubation. These findings indicate that precision-cut slices, in which KCs function is well preserved, are convenient but limited in vitro tools for the evaluation of transporter transcription, such as Mdrlb.

Transporter, TNF- $\alpha$ and iNOS transcription pattern varied among Gd- and normal-slices treated with SpNO (Figs. 4, 5). NO stimulates $\mathrm{O}_{2}^{-}$production in mitochondria, via inhibition of the respiratory chain and reaction with ubiquinol, and also accumulates $\mathrm{O}_{2}^{-}$due to the inhibition of mitochondrial superoxide dismutase. ${ }^{3)} 3$-Nitrotyrosine, a biomarker of $\mathrm{ONOO}^{-}$ formation, is detected in hepatocytes treated with $S$-nitroso$\mathrm{N}$-acetylpenicillamine, an NO donor, as well as SIN, indicating the intracellular $\mathrm{ONOO}^{-}$formation from exogenous $\mathrm{NO}^{25)}$ Therefore, we speculate that $\mathrm{NO}$ and $\mathrm{ONOO}^{-}$, a reaction product of $\mathrm{NO}$ from $\mathrm{SpNO}$ with cellular $\mathrm{O}_{2}^{-}$, may affect hepatocytes in Gd-slices treated with SpNO. As ROS levels in $\mathrm{KCs}$ is higher than those in sinusoidal endothelial cells even in basal conditions, ${ }^{30)}$ an intercellular oxidant balance between pro-oxidant $\mathrm{KCs}$ and anti-oxidant endothelial cells is suggested in the hepatic micro-environment. ${ }^{31)}$ Therefore, KCs may enhance both extracellular and intracellular $\mathrm{ONOO}^{-}$formation in normal-slices treated with SpNO.

The decrease of TNF- $\alpha$ and iNOS mRNA levels was observed in normal-slices with SpNO or SIN and Gd-slices with SIN, but not in Gd-slices with SpNO (Fig. 4). TNF- $\alpha$ and iNOS are NF- $\kappa \mathrm{B}$ target genes. ${ }^{28,29)} \mathrm{NO}$ and $\mathrm{ONOO}^{-}$ have been reported to inhibit NF- $\kappa \mathrm{B}$ activation. ${ }^{6,32)}$ Our results suggest that $\mathrm{ONOO}^{-}$play a prominent role in the inhibition of NF- $\kappa \mathrm{B}$ activation, and intracellular $\mathrm{ONOO}^{-}$levels obtained in Gd-slices with SpNO may be not enough to inhibit NF- $\kappa \mathrm{B}$ activation.

Transporter transcription patterns varied among Gd- and normal-slices treated with SpNO or SIN (Table 2). SpNO and SIN had no effect on Oatp1b2 transcription, which is in agreement with a study showing iNOS-independent regulation. ${ }^{33)}$ Similarly to the decrease of TNF- $\alpha$ and iNOS transcription as mentioned above, the transporter transcription pattern in Gd-slices with SpNO, the up-regulation of influx transporter Oatpla1 and the down-regulation of efflux transporter Mdr2, was completely different from those in normalslices with SpNO or SIN and Gd-slices with SIN. The pattern observed in the latter three cases was generally the down-regulation of influx and the up-regulation of efflux transporters, which are considered to be one compensatory mechanism to protect liver from the accumulation of endogenous and exogenous compounds. The exceptions were Ntcp in Gd-slices with SIN and Bsep and Mdr2 in normal-slices with SIN. The up-regulation of Oatp1a1 and Ntcp were observed in Gd-slices with SpNO and SIN, respectively, but not in normal-slices, suggesting a possible role of KCs in their transcriptional regulation. The transcription of Bsep and Mdr2, which are involved in bile formation as bile acids and phospholipids transporter, respectively, ${ }^{9)}$ was oppositely regulated by SpNO and SIN, the up-regulation and the downregulation, respectively, in normal-slices, suggesting a cytoprotective effect of NO. The up-regulation of basolateral efflux transporter Mrp3 was specific response to SIN. Consistent with a role of Mrp3 in the efflux of bile acids into blood in a compensatory mechanism, ${ }^{34)}$ the up-regulated Mrp3 was accompanied with the down-regulation of efflux transporter Bsep in normal-slices and the up-regulation of influx transporter Ntcp in Gd-slices, both are bile acids transporter.

The up-regulation of Mrp2, as well as the down-regulation of Oat2, was commonly observed in normal-slices with SpNO or SIN and Gd-slices with SIN, suggesting a role of $\mathrm{ONOO}^{-}$(Table 2). Proinflammatory cytokines have been reported to down-regulate Mrp2 transcription, ${ }^{5,35)}$ which may be suggested to be due to decreased nuclear protein levels of the nuclear receptor family. ${ }^{9)}$ Recent studies reported up-regulation of nuclear factor-E2-related factor (Nrf) 2 target genes by $\mathrm{ONOO}^{-}{ }^{36)}$ induction of Mrp2 by Nrf2 chemical activators $^{37)}$ and binding of Nrf2 to the Mrp2 promoter region. ${ }^{38)}$ Taken together, our results indicate that $\mathrm{ONOO}^{-} \mathrm{can}$ regulate Mrp2 transcription at least partly through the activation of Nrf2 binding. Despite $\mathrm{ONOO}^{-}$formation in both liver and kidney, ${ }^{39,40)}$ LPS decreases Mrp2 mRNA levels in the liver ${ }^{1,11)}$ and liver slices (Fig. 3), but increases Mrp2 
mRNA and protein levels in the kidney. ${ }^{40)}$ Further, Mrp2 mRNA, protein levels and its function in the liver increase in response to acetaminophen, ${ }^{41,42)}$ whose toxicity is related to $\mathrm{ONOO}^{-}$formation. ${ }^{43)}$ These finding suggest that Mrp2 transcription may be up-regulated by $\mathrm{ONOO}^{-}$under certain conditions, such as minor production of proinflammatory cytokines

In conclusion, our results show that $\mathrm{NO}$ and $\mathrm{ONOO}^{-}$regulate rat liver transporter transcription in a proinflammatory cytokine-independent manner, and that $\mathrm{KCs}$ play a critical role in $\mathrm{NO}$ and $\mathrm{O}_{2}^{-}$supply to form $\mathrm{ONOO}^{-}$, as well as in cellular communication with hepatocytes.

Acknowledgements We thank Dr. Geny M. M. Groothuis (Groningen Research Institute for Pharmacy, University of Groningen, the Netherlands) for the excellent advice on manipulation of precision-cut liver slices.

\section{REFERENCES}

1) Cherrington N. J., Slitt A. L., Li N., Klaassen C. D., Drug Metab. Dispos., 32, 734-741 (2004)

2) Billiar T. R., Curran R. D., Ferrari F. K., Williams D. L., Simmons R. L., J. Surg. Res., 48, 349-353 (1990).

3) Brown G. C., Borutaite V., Biochem. Soc. Trans., 34, 953-956 (2006)

4) Fernandez C., Buyse M., German-Fattal M., Gimenez F., J. Pharm. Pharm. Sci., 7, 359-371 (2004).

5) Geier A., Dietrich C. G., Voigt S., Ananthanarayanan M., Lammert F., Schmitz A., Trauner M., Wasmuth H. E., Boraschi D., Balasubramaniyan N., Suchy F. J., Matern S., Gartung C., Am. J. Physiol. Gastrointest. Liver Physiol., 289, G831-G841 (2005).

6) Peng H. B., Libby P., Liao J. K., J. Biol. Chem., 270, 14214-14219 (1995).

7) Kröncke K. D., Carlberg C., FASEB J., 14, 166-173 (2000).

8) de Lucas S., López-Alcorocho J. M., Bartolomé J., Carreño V., Biochem. Biophys. Res. Commun., 321, 688-694 (2004).

9) Trauner M., Boyer J. L., Physiol. Rev., 83, 633-671 (2003).

10) Cha S. H., Kim H. P., Jung N. H., Lee W. K., Kim J. Y., Cha Y. N., IUBMB Life, 54, 129-135 (2002).

11) Aoki K., Nakajima M., Hoshi Y., Saso N., Kato S., Sugiyama Y., Sato H., Biol. Pharm. Bull., 31, 412-420 (2008).

12) Olinga P., Merema M. T., de Jager M. H., Derks F., Melgert B. N., Moshage H., Slooff M. J., Meijer D. K., Poelstra K., Groothuis G. M., J. Hepatol., 35, 187-194 (2001).

13) Liu P., McGuire G. M., Fisher M. A., Farhood A., Smith C. W., Jaeschke H., Shock, 3, 56-62 (1995).

14) Roland C. R., Naziruddin B., Mohanakumar T., Flye M. W., J. Leukoc. Biol., 60, 487-492 (1996).

15) Vollmar B., Rüttinger D., Wanner G. A., Leiderer R., Menger M. D., Shock, 6, 434-441 (1996).

16) Elferink M. G., Olinga P., Draaisma A. L., Merema M. T., Farber K. N., Slooff M. J., Meijer D. K., Groothuis G. M., Am. J. Physiol. Gastrointest. Liver Physiol., 287, G1008-G1016 (2004).
17) Brown A. P., Harkema J. R., Schultze A. E., Roth R. A., Ganey P. E., Shock, 7, 186-192 (1997).

18) Misko T. P., Schilling R. J., Salvemini D., Moore W. M., Currie M. G., Anal. Biochem., 214, 11-16 (1993).

19) Liang D., Hagenbuch B., Stieger B., Meier P. J., Hepatology, 18 1162-1166 (1993).

20) Rippin S. J., Hagenbuch B., Meier P. J., Stieger B., Hepatology, 33 $776-782(2001)$.

21) Jigorel E., Le Vee M., Boursier-Neyret C., Bertrand M., Fardel O., Drug Metab. Dispos., 33, 1418-1422 (2005).

22) Nishimura M., Koeda A., Suzuki E., Kawano Y., Nakayama M., Satoh T., Narimatsu S., Naito S., Drug Metab. Pharmacokinet, 21, 297-307 (2006).

23) Salkowski C. A., Neta R., Wynn T. A., Strassmann G., van Rooijen N., Vogel S. N., J. Immunol., 155, 3168-3179 (1995).

24) McInnes I. B., Leung B. P., Field M., Wei X. Q., Huang F. P., Sturrock R. D., Kinninmonth A., Weidner J., Mumford R., Liew F. Y., J. Exp. Med., 184, 1519-1524 (1996).

25) D’Ambrosio S. M., Oberyszyn T. M., Brady T., Ross M. S., Robertson F. M., Biochem. Biophys. Res. Commun., 233, 545-549 (1997).

26) Ziemann C., Bürkle A., Kahl G. F., Hirsch-Ernst K. I., Carcinogenesis, 20, 407-414 (1999).

27) Ros J. E., Schuetz J. D., Geuken M., Streetz K., Moshage H., Kuipers F., Manns M. P., Jansen P. L., Trautwein C., Müller M., Hepatology, 33, 1425-1431 (2001).

28) Xie Q. W., Kashiwabara Y., Nathan C., J. Biol. Chem., 269, 47054708 (1994).

29) Kuprash D. V., Udalova I. A., Turetskaya R. L., Rice N. R., Nedospasov S. A., Oncogene, 11, 97-106 (1995).

30) Catalá M., Pagani R., Portolés M. T., Histol. Histopathol., 22, 399407 (2007).

31) Spolarics Z., J. Leukoc. Biol., 63, 534-541 (1998).

32) Levrand S., Pesse B., Feihl F., Waeber B., Pacher P., Rolli J., Schaller M. D., Liaudet L., J. Biol. Chem., 280, 34878-34887 (2005).

33) Li N., Klaassen C. D., Toxicol. Sci., 83, 197-203 (2005)

34) Kusuhara H., Sugiyama Y., J. Controlled Release, 78, 43-54 (2002).

35) Siewert E., Dietrich C. G., Lammert F., Heinrich P. C., Matern S., Gartung C., Geier A., Biochem. Biophys. Res. Commun., 322, 232-238 (2004).

36) Park E. Y., Kim S. G., Methods Enzymol., 396, 341-349 (2005).

37) Maher J. M., Cheng X., Slitt A. L., Dieter M. Z., Klaassen C. D., Drug Metab. Dispos., 33, 956-962 (2005).

38) Vollrath V., Wielandt A. M., Iruretagoyena M., Chianale J., Biochem. J., 395, 599-609 (2006)

39) Cuzzocrea S., Mazzon E., Di Paola R., Esposito E., Macarthur H., Matuschak G. M., Salvemini D., J. Pharmacol. Exp. Ther., 319, 73-81 (2006).

40) Heemskerk S., van Koppen A., van den Broek L., Poelen G. J., Wouterse A. C., Dijkman H. B., Russel F. G., Masereeuw R., Pflugers Arch., 454, 321-334 (2007).

41) Ghanem C. I., Gómez P. C., Arana M. C., Perassolo M., Ruiz M. L., Villanueva S. S., Ochoa E. J., Catania V. A., Bengochea L. A., Mottino A. D., Biochem. Pharmacol., 68, 791-798 (2004).

42) Aleksunes L. M., Slitt A. M., Cherrington N. J., Thibodeau M. S., Klaassen C. D., Manautou J. E., Toxicol. Sci., 83, 44-52 (2005).

43) Knight T. R., Kurtz A., Bajt M. L., Hinson J. A., Jaeschke H., Toxicol. Sci., 62, 212-220 (2001). 